\title{
Preparation and Swelling Behavior of L-Lactide Interpenetrating Networks
}

\author{
Zainab J. Sweah, Hadi S. Al-Lami, Athir M. Haddad* \\ Department of Chemistry, College of science, University of Basrah Garmat Ali, Basrah, Iraq \\ Email: *athirhaddad@yahoo.com
}

How to cite this paper: Sweah, Z.J., AlLami, H.S. and Haddad, A.M. (2016) Preparation and Swelling Behavior of LLactide Interpenetrating Networks. Open Journal of Organic Polymer Materials, 6, 119-133.

http://dx.doi.org/10.4236/ojopm.2016.64012

Received: September 21, 2016

Accepted: October 28, 2016

Published: October 31, 2016

Copyright $\odot 2016$ by authors and Scientific Research Publishing Inc. This work is licensed under the Creative Commons Attribution International License (CC BY 4.0).

http://creativecommons.org/licenses/by/4.0/

\begin{abstract}
Novel triblock copolymers of poly (L-lactide)-poly (ethylene glycol)-sebacate-poly (ethylene glycol)-poly (L-lactide) were synthesized by Ring-Opening Polymerization of different ratios of L-lactide with other three pre-prepared poly (ethylene glycol)sebacate-poly (ethylene glycol) polymers, coded A, B and C which had different poly (ethyleneglycol) chain lengths. The copolymers were characterized by FTIR and ${ }^{1} \mathrm{H}$ NMR spectroscopy, which indicated that the reaction of ROP took place and led to producing nine triblock copolymers having new different lactide chain lengths $(\mathrm{n}=$ 10, 25 and 50), $\mathrm{AL}_{10}, \mathrm{AL}_{25}, \mathrm{AL}_{50}, \mathrm{BL}_{10}, \mathrm{BL}_{25}, \mathrm{BL}_{50}, \mathrm{CL}_{10}, \mathrm{CL}_{25}$, and $\mathrm{CL}_{50}$. Nine polymer networks were also prepared from copolymers with sodium alginate $S_{1}-S_{9}$ and finally mixed with a solution of hydroxyl ethyl cellulose to form $\mathrm{SH}_{1}-\mathrm{SH}_{9}$.
\end{abstract}

\section{Keywords}

Lactide Copolymers, Ring-Opening Polymerization, Interpenetrating Polymer Networks (IPN's), Swelling Ratio

\section{Introduction}

In polymer chemistry, Ring-Opening Polymerization (ROP) is a form of chain-growth polymerization. At the terminal end of a polymer chain, it acts as a reactive center where further cyclic monomers can react by opening its ring system and form a long polymer chain. The propagation center can be radical, anionic or cationic. Some cyclic monomers such as lactide and glycolide can be polymerized to high molecular weight polymers by using metal catalysts. ROP continues to be the most versatile method of major groups of biopolymers, particularly when they are required in quantity. Commonly, the monomers in ROP are rings irrespective of ring size, but the reason why polymerization takes place can vary. Rings composed of $3-8$ atoms may polymerize 
due to the loss of enthalpy associated with the loss of ring strain as oxiranes, lactones, lactams, and lactide [1] [2] [3] [4]. ROP is important to produce some industrial polymers like polyethylene oxide and polysiloxanes. The activation of initiating and propagating alcohols by strong nonionic bases can be utilized to enable the polymerization of strained cyclic ester monomers, such as lactide. The (1,8-diazabicyclio[5.4.0] undec7-ene) DBU, (7-methyl-1,5,7-triazabicyclo[4.4.0]dec-5-ene) MTBD and TBD (general structure of a phosphazene base) are highly active catalysts for this ROP process, providing Degree of Polymerization DP 500 PLAs within a few minutes at room temperature and $1 \mathrm{~mol} \%$ catalysts loadings [5] [6] [7]. Haitao Qian, et al. [8] used DBU, a known, effective, and convenient organ catalyst, for the ring opening polymerization of cyclic esters, to synthesize random copolymers of lactide and glycolide. In contrast, the application of DBU to catalyze the ROP resulted in polymers with predictable molecular weights and narrow PDIs $(<1.09)$.

End-group fidelity of the polymerization can be determined by both ${ }^{1} \mathrm{H}$ NMR and Gel-Permeation Chromatography (GPC) technique [9]. Polymerizations mediated by DBU also showed a linear increase of molecular weight with monomer conversion. DBU is a strictly hindered amidine that has demonstrated usefulness in a variety of different reactions.

\section{Experiment}

\subsection{Materials}

Chemicals used in this study were supplied from different sources, polyethylene glycol (average M. wt. 2000, 4000 and 10000) were supplied from BDH Co., sebacoyl chloride and glutaraldehyde were supplied from Fluka Co.,1,2-dichloro ethane (EDC) was supplied from Lab Co., triethylamine was supplied from $\mathrm{RDH}$ Co., L-lactide was supplied from BDH Co., Diazabicyclo [5.4.0] undec-7-ene (DBU), diethyl ether and hydroxy ethyl cellulose were supplied from Sigma-Aldrich Co., sodium alginate was supplied from HIMEDIA Co., all materials were used without any purification.

\subsection{Instruments}

FTIR-Jasco 4200 supplied by JASCO Company was used for recording I.R spectra of the new polymers as $\mathrm{KBr}$ disc from $(400-4000) \mathrm{cm}^{-1}$. The ${ }^{1} \mathrm{H}$ NMR was recorded using Bruker $400 \mathrm{MHz}$ spectrometer. Type INSPECT S50 supplied by FEI Company. Polymers molecular weights and molecular weight distributions $\left(M_{w} / M_{n}\right)$ were determined using a Waters 1515 gel permeation chromatography (GPC); DMF was used as the eluent at a flow rate of $1.0 \mathrm{ml} / \mathrm{min}$ and calibrated with polymethyl methacrylate standard

\subsection{Preparation of Polymers}

\subsubsection{Preparation of Poly (Ethylene Glycol)-Sebacate-Poly (Ethylene Glycol)} (A)

Poly (ethylene glycol), PEG, (M. Wt. 2000) (40 g, 0.02 moles), ( $2.79 \mathrm{ml}, 0.02$ moles) of 
triethyl amine (TEA) were dissolved in $50 \mathrm{ml}$ of 1,2-dichloroethane (EDC). Sebacoyl chloride (SC) (2.14 ml, 0.01 mole) was dissolved in $10 \mathrm{ml}$ of EDC and then added drop wise into the mixed solution. The reaction was kept under argon for 24 hours at room temperature with continuous stirring on a magnetic stirrer. The reaction was worked up by a slow addition of the product to $500 \mathrm{ml}$ cold diethyl ether to precipitate the polymer, filtered on a Buchner funnel and washed with diethyl ether, and dried in vacuum oven at $25^{\circ} \mathrm{C}$ for 24 hours [10].

${ }^{1} \mathrm{H}-\mathrm{NMR}$ and FTIR was measured and the yield of the product was $78 \%$. The same procedure was carried out to prepare the polymers B and C, the yield of polymer B was $90 \%$ and polymer $\mathrm{C}$ was $87 \%$. The reaction is represented in Scheme 1 and Table 1 shows the materials used.

\subsubsection{Preparation of Poly (L-Lactide)-Poly (Ethylene Glycol)-Sebacate-Poly (Ethylene Glycol)-Poly (L-Lactide) Triblock Copolymers (LA 10$)$}

The triblock copolymers were synthesized by ROP of (L-lactide) with prepared polymer (A) in the presence of DBU as catalyst [11]. Briefly, the polymer (A) (4.168 g, 0.001 mole) was added to (L-lactide) (PLLA) (1.44 g, 0.01 mole) was dissolved in $75 \mathrm{ml}$ of EDC in three neck flask equipped with argon gas. DBU $(55 \mu \mathrm{L})$ was added and the mixture was stirred for 24 hours at $25^{\circ} \mathrm{C}$ under Argon atmosphere. The reaction was worked up by the slow addition of the reactants to $500 \mathrm{ml}$ diethyl ether to precipitate the polymer, which was then filtered on a Buchner funnel, washed with diethyl ether, and then dried in vacuum oven at $25^{\circ} \mathrm{C}$ for 24 hours.

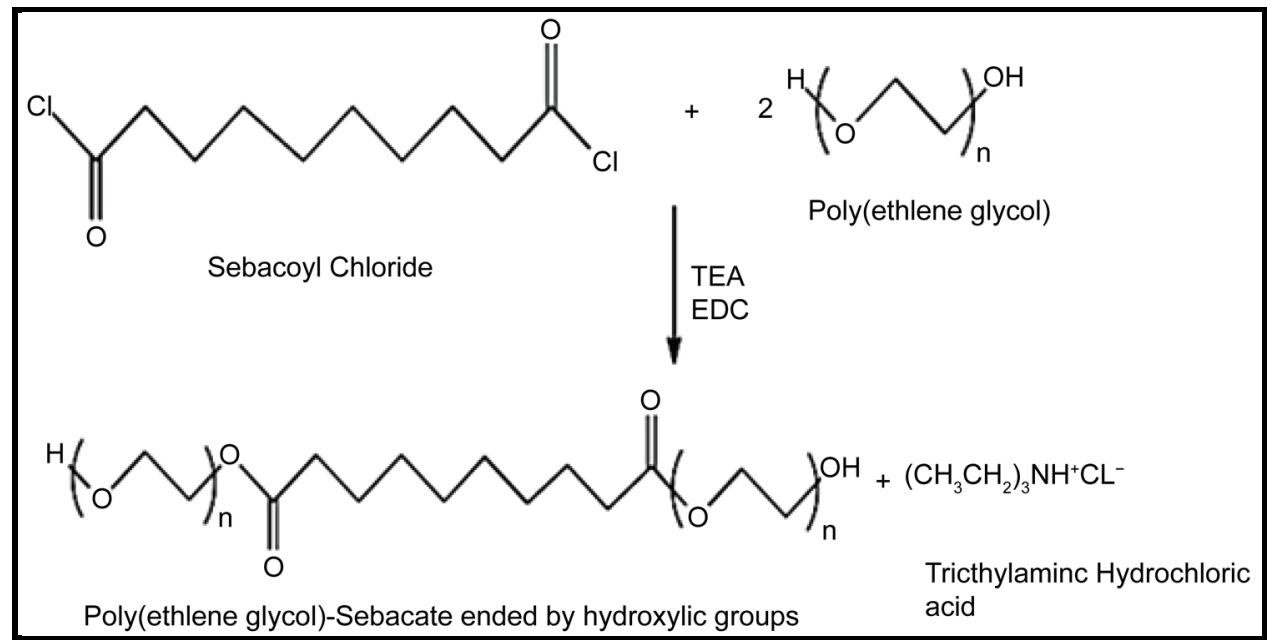

Scheme 1. Chemical equations of preparation of poly (ethylene glycol)-sebacate-poly (ethylene glycol) (2000, 4000, and 10000).

Table 1. Composition of materials for preparation of polymers B, and C.

\begin{tabular}{ccccc}
\hline Polymer & PEG $(\mathrm{g})$ & PEG (mole) & SC (mole) & TEA (mole) \\
\hline B & 20 & 0.002 & 0.001 & 0.002 \\
C & 8 & 0.002 & 0.001 & 0.002 \\
\hline
\end{tabular}


The same procedure was carried out to prepare the polymers $\mathrm{AL}_{25}, \mathrm{AL}_{50}, \mathrm{BL}_{10}, \mathrm{BL}_{25}$, $\mathrm{BL}_{50}, \mathrm{CL}_{10}, \mathrm{CL}_{25}$, and $\mathrm{CL}_{50}$. The chemical equations can be represented by the Scheme 2 and Table 2 shows the quantities of reactants used in the preparation of the polymers, $\mathrm{AL}_{25}, \mathrm{AL}_{50}, \mathrm{BL}_{10}, \mathrm{BL}_{25}, \mathrm{BL}_{50}, \mathrm{CL}_{10}, \mathrm{CL}_{25}$, and $\mathrm{CL}_{50}$.

\subsubsection{Preparation of Network $\mathrm{S}_{1}$}

$0.4 \mathrm{~g}$ of $\mathrm{AL}_{10}, 0.4 \mathrm{~g}$ of sodium alginate (Na-alg.) were dissolved in $5 \mathrm{ml}$ distilled water (solution A), $0.1 \mathrm{~g}$ of calcium chloride was dissolved in $5 \mathrm{ml}$ distilled water (solution $\mathrm{B}$ ). Solution A was added drop wise to solution B to form polymeric beads. These beads were collected and washed with water two times and dried to obtain $S_{1}$. The same procedure was carried out to prepare networks $S_{2}-S_{9}[12]$.

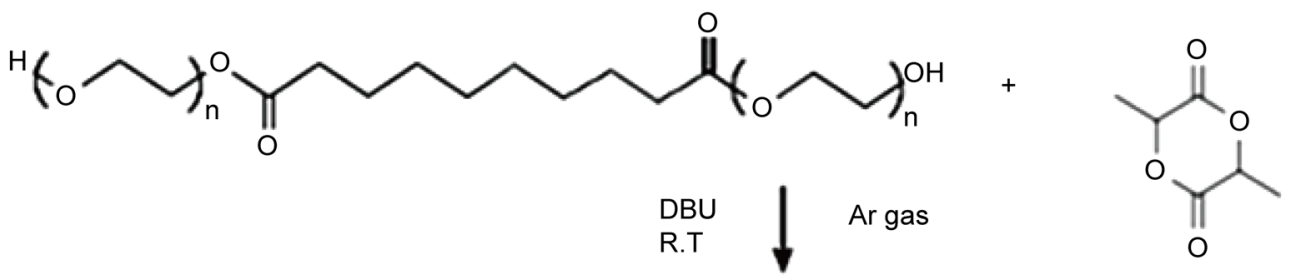

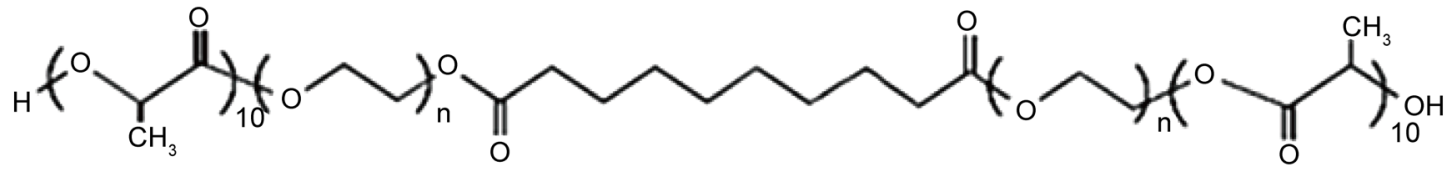

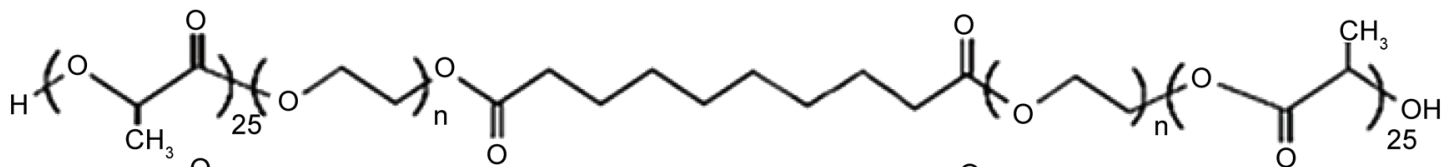<smiles>CC(C)OC(=O)CCCCCCCCC(=O)OCCC(C)(C)OCCC(C)(C)OC(=O)C(C)C(=O)C(C)OC(C)(C)O</smiles>

Scheme 2. Chemical equations of preparation of triblock copolymers $\mathrm{AL}_{10}, \mathrm{AL}_{25}$, and $\mathrm{AL}_{50}$ from polymer $\mathrm{A}$ with $\mathrm{L}-\mathrm{Lactide}(\mathrm{PEG}=2000)$.

Table 2. The composition of prepared block polymers $\mathrm{AL}_{10}, \mathrm{AL}_{25}, \mathrm{AL}_{50}, \mathrm{BL}_{10}, \mathrm{BL}_{25}, \mathrm{BL}_{50}, \mathrm{CL}_{10}, \mathrm{CL}_{25}$, and $\mathrm{CL}_{50}$.

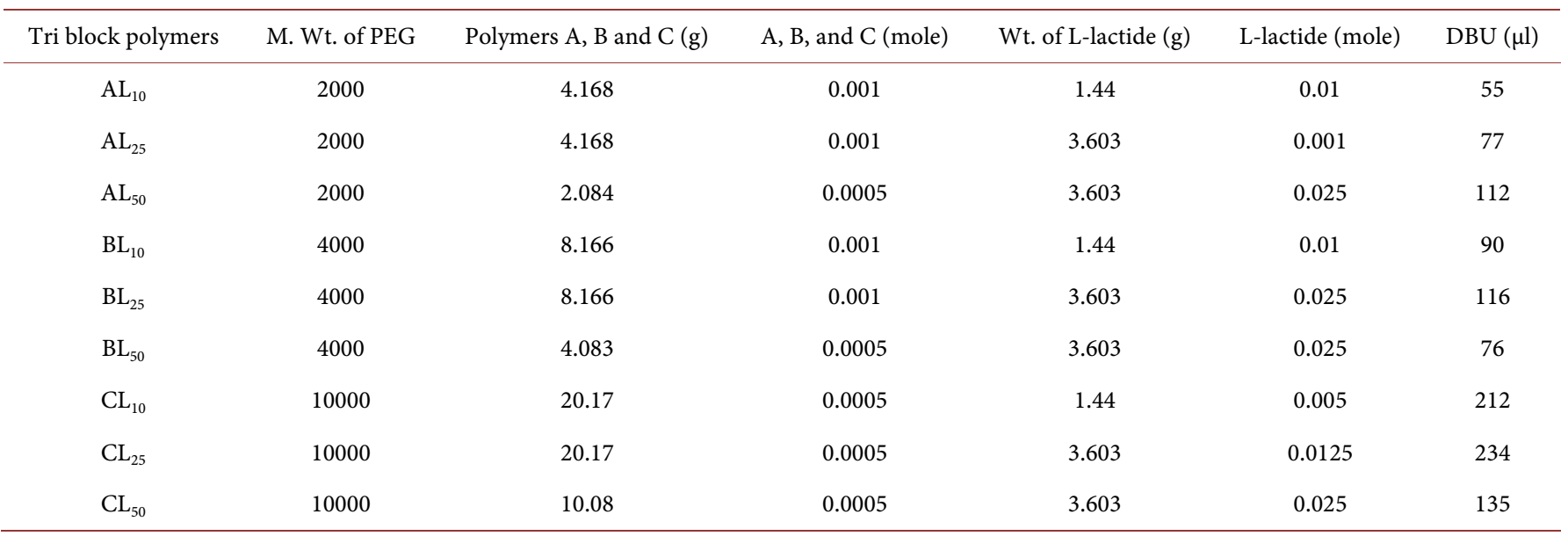




\subsubsection{Preparation of Fibers IPN's $\mathrm{SH}_{1}-\mathrm{SH}_{9}$}

$0.4 \mathrm{~g}$ of hydroxyethylcellulose (HEC), $377 \mu \mathrm{l}$ glutraldehyde and $0.25 \mathrm{ml}$ of concentration of sulfuric acid were heated with continuous stirring at $60^{\circ} \mathrm{C}-65^{\circ} \mathrm{C}$ for one hour. Then the crosslinked product solution was cooled. The cold solution of crosslinked HEC was mixed with $0.4 \mathrm{~g}$ of $\mathrm{S}_{1}$ in an ice bath with continuous stirring for half an hour. The product was then dried in vacuum oven at $25^{\circ} \mathrm{C}$, ground and pressed as discs. The same procedure was carried out to prepare of fiber IPN's $\mathrm{SH}_{2}-\mathrm{SH}_{9}$.

\section{Results and Discussion}

The FTIR spectra of (A, B, and C) polymers with the characteristic absorption bands were intense due to the associated hydroxyl groups $\left(3434,3498\right.$, and $3447 \mathrm{~cm}^{-1}$ ) and bands at $\left(2883,2885\right.$, and $\left.2887 \mathrm{~cm}^{-1}\right)$ for $\left(\mathrm{CH}_{2}\right)$ of PEG repeated units. Representative I.R. spectrum is shown in Figure 1. The intensity of the hydroxyl group band was decreased with increasing PEG molecular weight, the same observation was made by Jalal and Al-Lami [13]. The appearance of the stretching band of $(\mathrm{C}=\mathrm{O})$ at $1725 \mathrm{~cm}^{-1}$ as a result of esterfication reaction of PEG with SC show less intensity due to the loss ratio of SC comparing to the molecular weight of PEG.

Representative I.R. spectrum of triblock copolymers of PLA-PEG-SC-PEG-PLA $\left(\mathrm{AL}_{10}\right)$ is shown in Figure 2. The characteristic absorption bands were intense bands due to the associated hydroxyl groups $\left(3417,3436\right.$, and $\left.3450 \mathrm{~cm}^{-1}\right)$. In the block copolymers spectrum, the sharp and intense bands at $\left(1741,1750\right.$, and $\left.1738 \mathrm{~cm}^{-1}\right)$, bands at $(1280$ $\left.\mathrm{cm}^{-1}\right)$ for $(\mathrm{C}-\mathrm{O})$ groups, and bands at $\left(2882,2883 \mathrm{~cm}^{-1}\right)$ for $\left(\mathrm{CH}_{2}\right)$ of PEG repeated units these bands confirm the presence of the carboxylic ester $(\mathrm{C}=\mathrm{O})$ and ether $(\mathrm{C}-\mathrm{O}-\mathrm{C})$

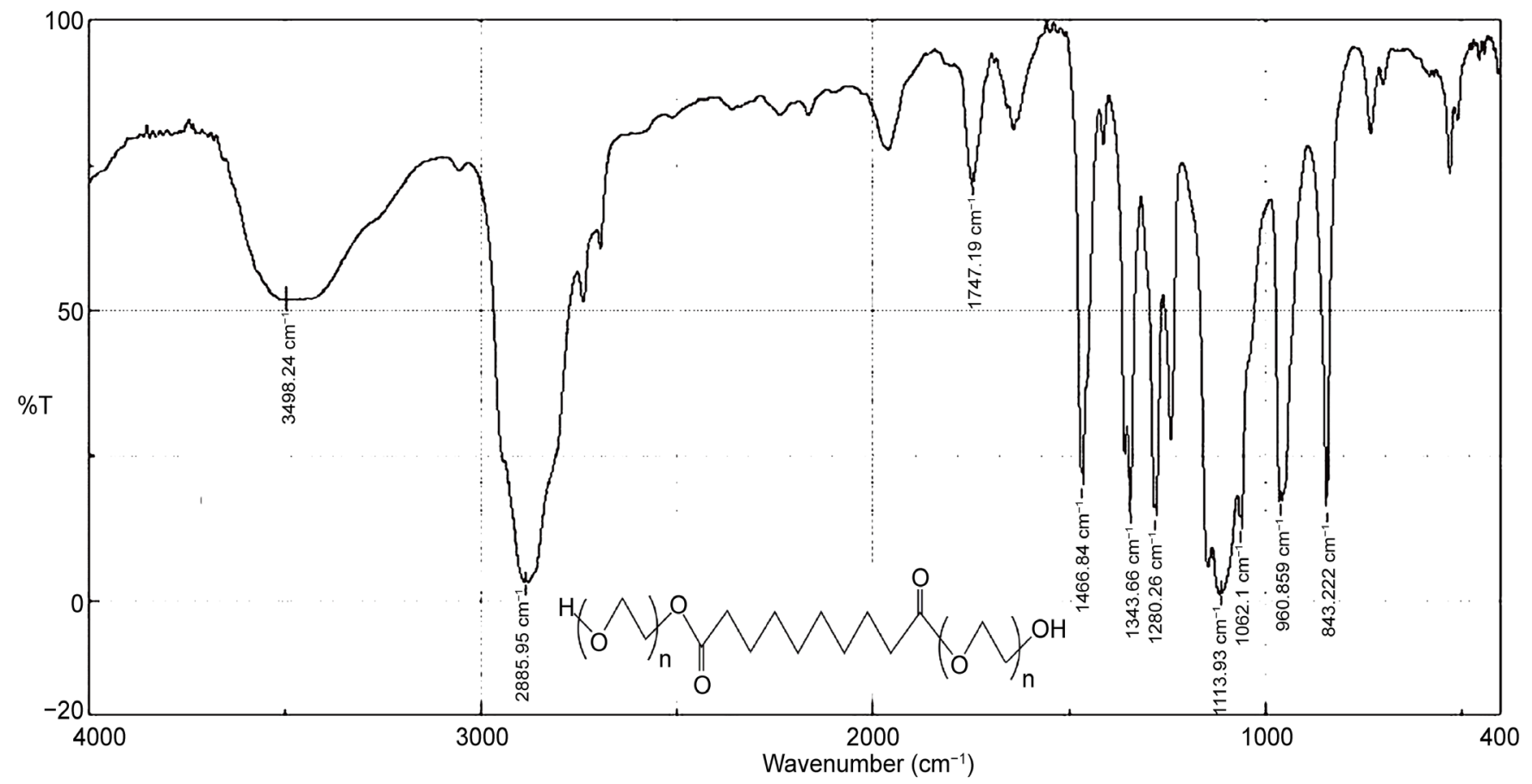

Figure 1. FTIR spectrum of poly (ethylene glycol)-sebacate-poly (ethylene glycol) (with PEG 2000), polymer (A). 


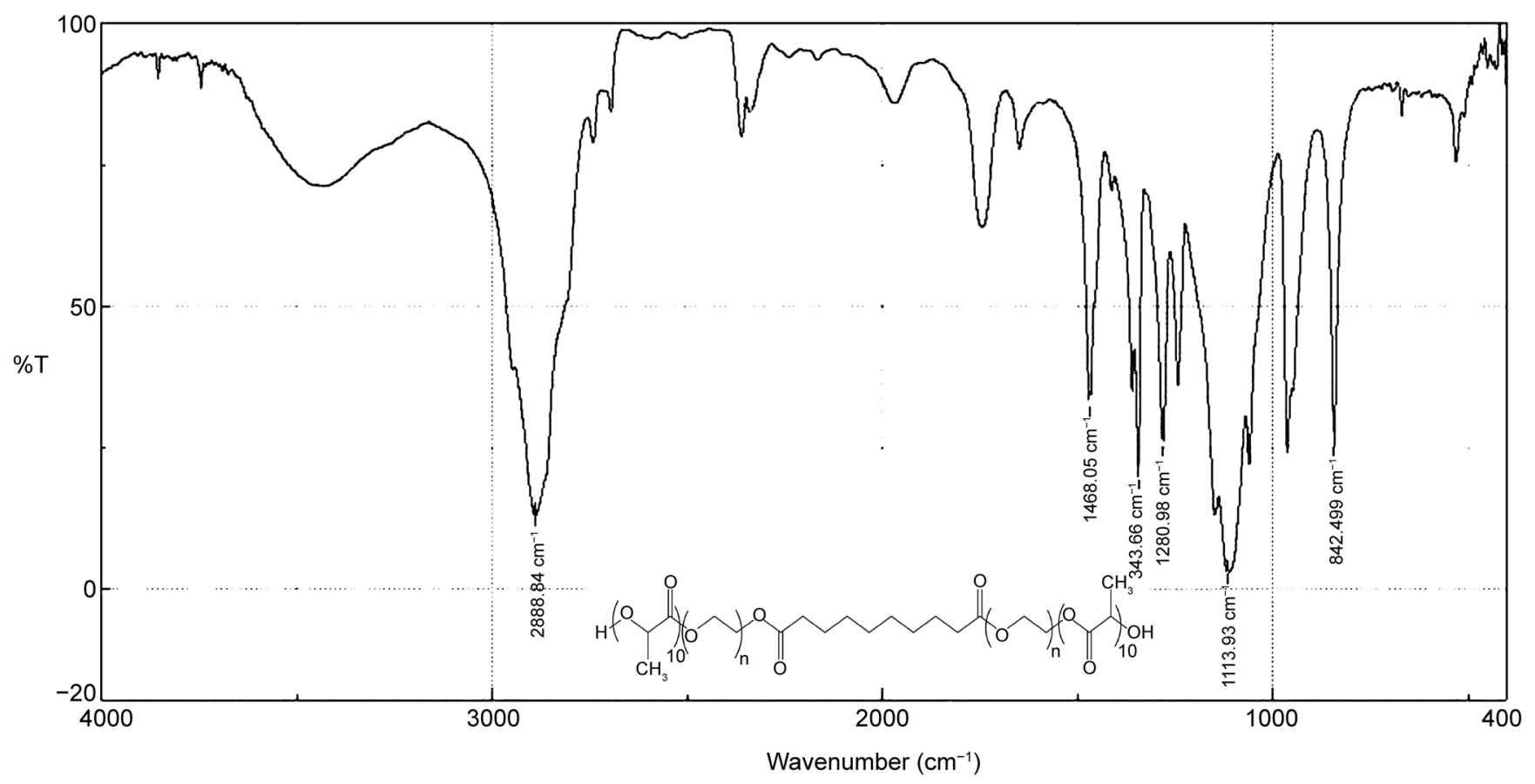

Figure 2. FTIR spectrum of triblock copolymer $\mathrm{AL}_{10}$.

groups indicating that the formation of the PLA-PEG-SC-PEG-PLA block copolymers has taken place. By increasing the PLA chain length, the band associated with hydroxyl group would be less intense, increasing the band's intensity of carboxylic ester $(\mathrm{C}=\mathrm{O})$ and (C-O) groups was due to the increasing of molecular weight of the block copolymer with increasing the ratio of PLA in the copolymer, which caused less stretching for the hydroxyl group with increasing stretching of carboxyl one, and that confirmed that the reaction take place [14].

${ }^{1} \mathrm{H}$ NMR technique was used to confirm the structure of the new prepared triblock copolymers (AL10, $\mathrm{AL}_{25}, \mathrm{AL}_{50}, \mathrm{BL}_{10}, \mathrm{BL}_{25}, \mathrm{BL}_{50}, \mathrm{CL}_{10}, \mathrm{CL}_{25}$, and $\left.\mathrm{CL}_{50}\right) .{ }^{1} \mathrm{H} \mathrm{NMR}$ of $(\mathrm{A}, \mathrm{B}$, and C) polymers and triblock copolymers of PLA-PEG-SC-PEG-PLA were recorded on a Bruker $400 \mathrm{MHz}$ spectrometer, using $\mathrm{CDCl}_{3}$ (Sigma-Aldrich, 99.8\% atom D). Figure 3 shows the NMR spectrum of poly (ethylene glycol)-sebacate-poly (ethylene glycol) having (PEG 2000), polymer A; the methylene protons in $\left(\mathrm{CH}_{2}\right)$ group of PEG were around $3.65 \mathrm{ppm}$ ( $\mathrm{a}$ and $\mathrm{b}$ ), the peaks at $2.2 \mathrm{ppm}$ represented the end methylene protons $\left(\mathrm{CH}_{2}\right)$ of sebcoyl chloride bonded to PEG segments, and at 2 ppm represented the methylene $\left(\mathrm{CH}_{2}\right)$ protons non bonded. The same position peaks were appeared for polymer $\mathrm{B}$ and $\mathrm{C}$.

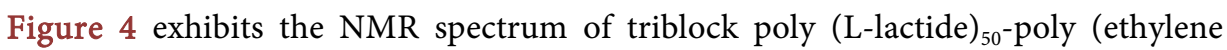
glycol)-sebacate-poly (ethylene glycol)-poly (L-lactide) $)_{50}\left(\mathrm{CL}_{50}\right)$, indicate the presence of methine $(\mathrm{CH})$ and Methyl $\left(\mathrm{CH}_{3}\right)$ protons in PLA was observed around $4.3 \mathrm{ppm}$ (c) for $(\mathrm{CH})$ of end group and around 5.2 to the $(\mathrm{CH})$ bonded inside the polymer chain, and 1.3 - $1.5 \mathrm{ppm}(\mathrm{d}, \mathrm{b})$, for the $\left(\mathrm{CH}_{3}\right)$ end group and inside group respectively. The methylene protons in $\left(\mathrm{CH}_{2}\right)$ group of PEG were around $3.65 \mathrm{ppm}$ (e and $\mathrm{f}$ ), the peaks at 2 


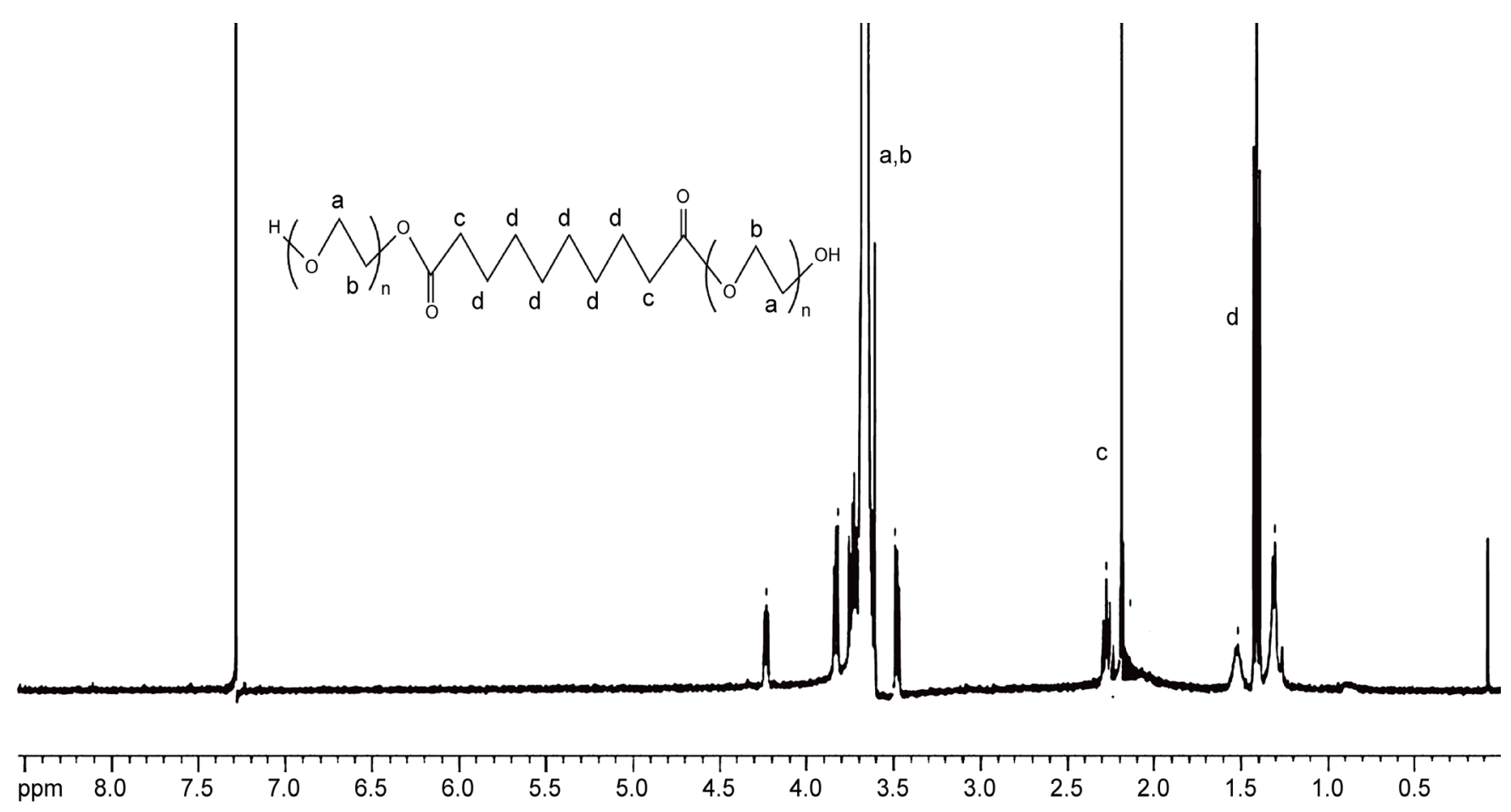

Figure 3. NMR spectrum of poly (ethylene glycol)-sebacate-poly (ethylene glycol) having (PEG 2000), polymer A.

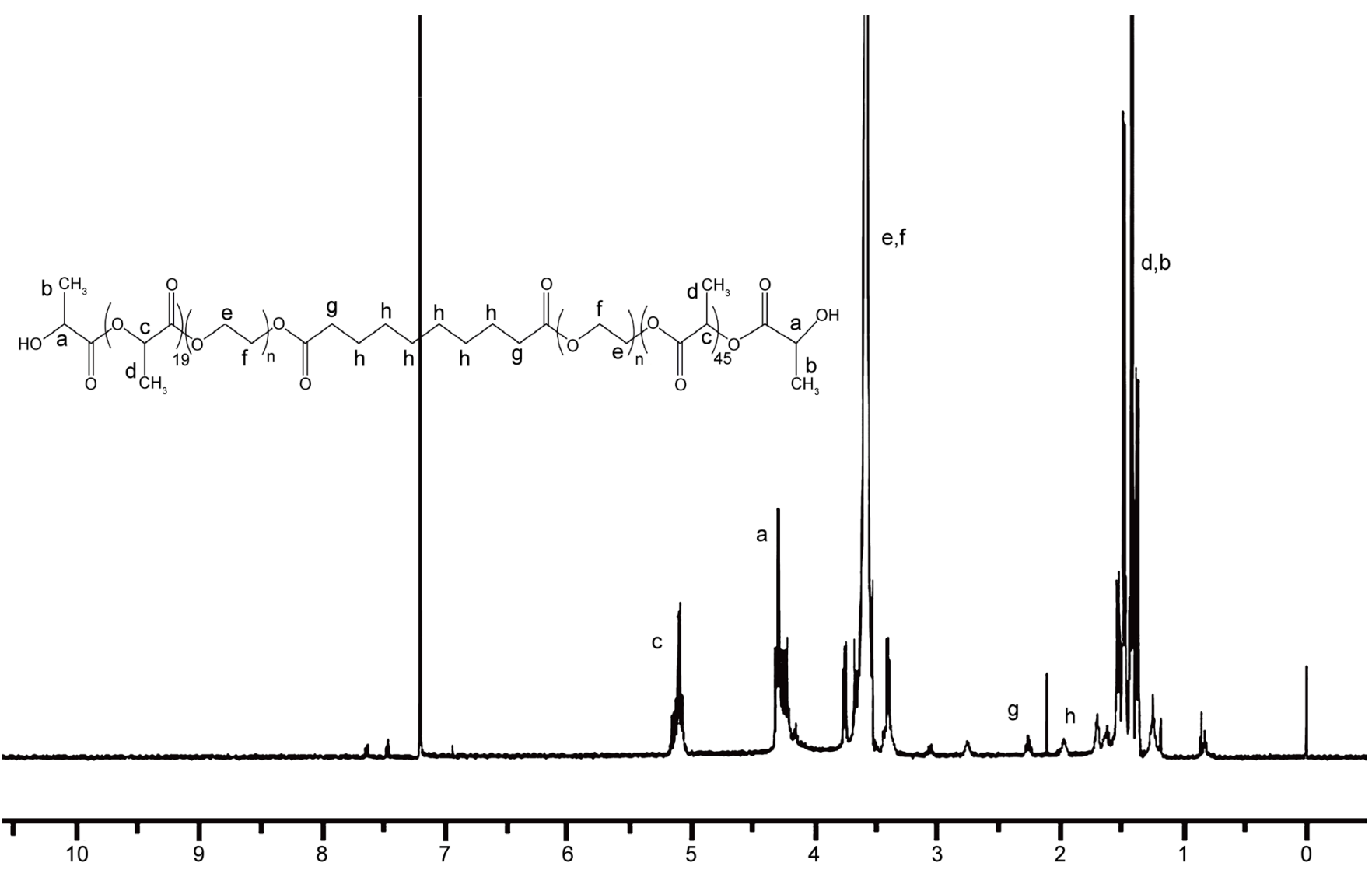

Figure 4. NMR spectrum of triblock poly (L-lactide) ${ }_{50}$-poly (ethylene glycol)-sebacate-poly (ethylene glycol)-poly $(\mathrm{L}-\mathrm{lactide})_{50}\left(\mathrm{CL}_{50}\right)$. 
ppm (g) represented the end methylene protons $\left(\mathrm{CH}_{2}\right)$ in the sebcoyl chloride bonded to PEG segments, the peak at $2.2 \mathrm{ppm}$ (h) represented methylene protons $\left(\mathrm{CH}_{2}\right)$ of sebcoyl chloride non bonded, the figure is very similar to the previously reported spectrum [15] [16], and confirm the synthesis of the PLA-PEG-SC-PEG-PLA block copolymers with three different units $(10,25$, and 50 units) on the end of the bis-poly (ethylene glycol) sebacate.

The molecular weight distributions $(\mathrm{Mw} / \mathrm{Mn})$ were calculated for all prepared triblock copolymers and Table 3 shows the GPC results. It appears that the PDI is ranging between $1.02-1.10$ indicating that the copolymers molecular weight distribution is nearly monodispers or from narrow distribution type. All these results are confirmed the expected structure and composition of the prepared copolymers and promoted this matter with great accuracy the results of GPC as shown significant closely with theoretical calculations of molecular weight and result the awesome polydispersity index (PDI) is close to one.

The examination of the morphology and fiber geometry of the IPN's was performed by using SEM. Figure 5 shows the SEM images of uncoated xerogel IPN's which demonstrated the fibers of the prepared IPN's. The size of the fibers was found to be in the range of (48 - 97) $\mathrm{nm}$ and the images of SEM measurements showed the clarity in the fibrous characterization of the IPN's with increasing the PLA chain length. Prior to be used as tissue engineering scaffolds, alginate-based materials need to be crosslinked to preserve their structure in an aqueous environment. Ionic crosslinking with divalent ions (e.g. $\mathrm{Ca}^{2+}$ ) avoids potentially toxic materials used in chemical crosslinking reactions.

From the figure, it is easy to observe the presence of spherical structures due to crosslinking of sodium alginate by divalent calcium ion. Also, the SEM images reveal that it is possible for the nanofibers to cover the surfaces of particles and the gaps between them [17]. The miscibility of ethylene oxide in the pegelated lactide and alginate may explain the smoothness of the surface exhibited in the SEM micrograph. It is known that a single polymer cannot satisfy all the requirements of an ideal biomaterial,

Table 3. Molecular weights and polydispersity index obtained from GPC measurements.

\begin{tabular}{ccccc}
\hline Triblock copolymer & Calculated M. Wt & Mn (GPC) & Mw (GPC) & PDI \\
\hline $\mathrm{AL}_{10}$ & 5642 & 5685 & 5861 & 1.03 \\
$\mathrm{AL}_{25}$ & 7802 & 8084 & 8603 & 1.06 \\
$\mathrm{AL}_{50}$ & 11,402 & 11,845 & 12,070 & 1.02 \\
$\mathrm{BL}_{10}$ & 9642 & 9772 & 10,037 & 1.03 \\
$\mathrm{BL}_{25}$ & 11,802 & 11,782 & 12,611 & 1.07 \\
$\mathrm{BL}_{50}$ & 15,402 & 15,250 & 15,590 & 1.02 \\
$\mathrm{CL}_{10}$ & 21,642 & 21,758 & 23,446 & 1.07 \\
$\mathrm{CL}_{25}$ & 23,802 & 24,014 & 25,500 & 1.06 \\
$\mathrm{CL}_{50}$ & 27,402 & 27,453 & 30,323 & 1.10 \\
\hline
\end{tabular}




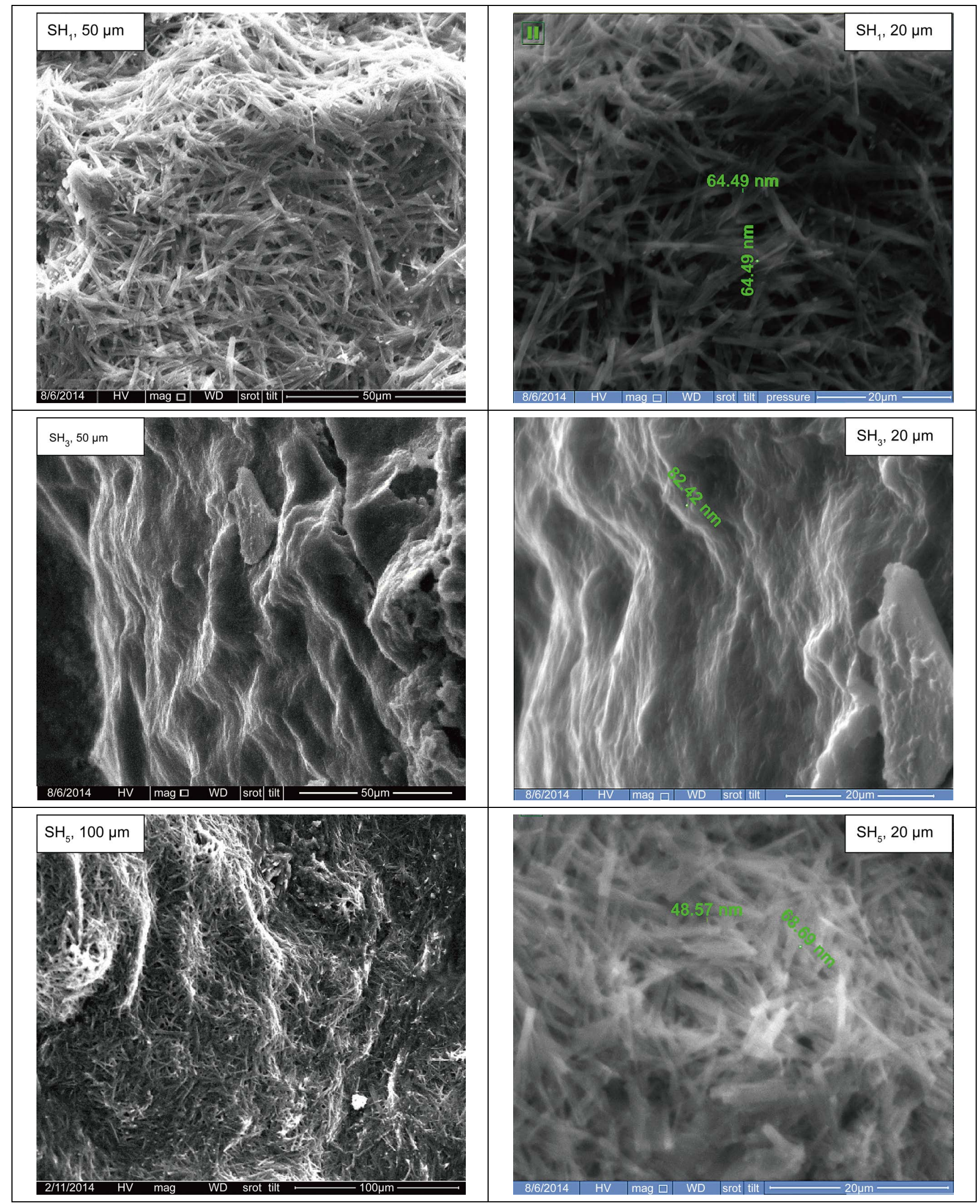




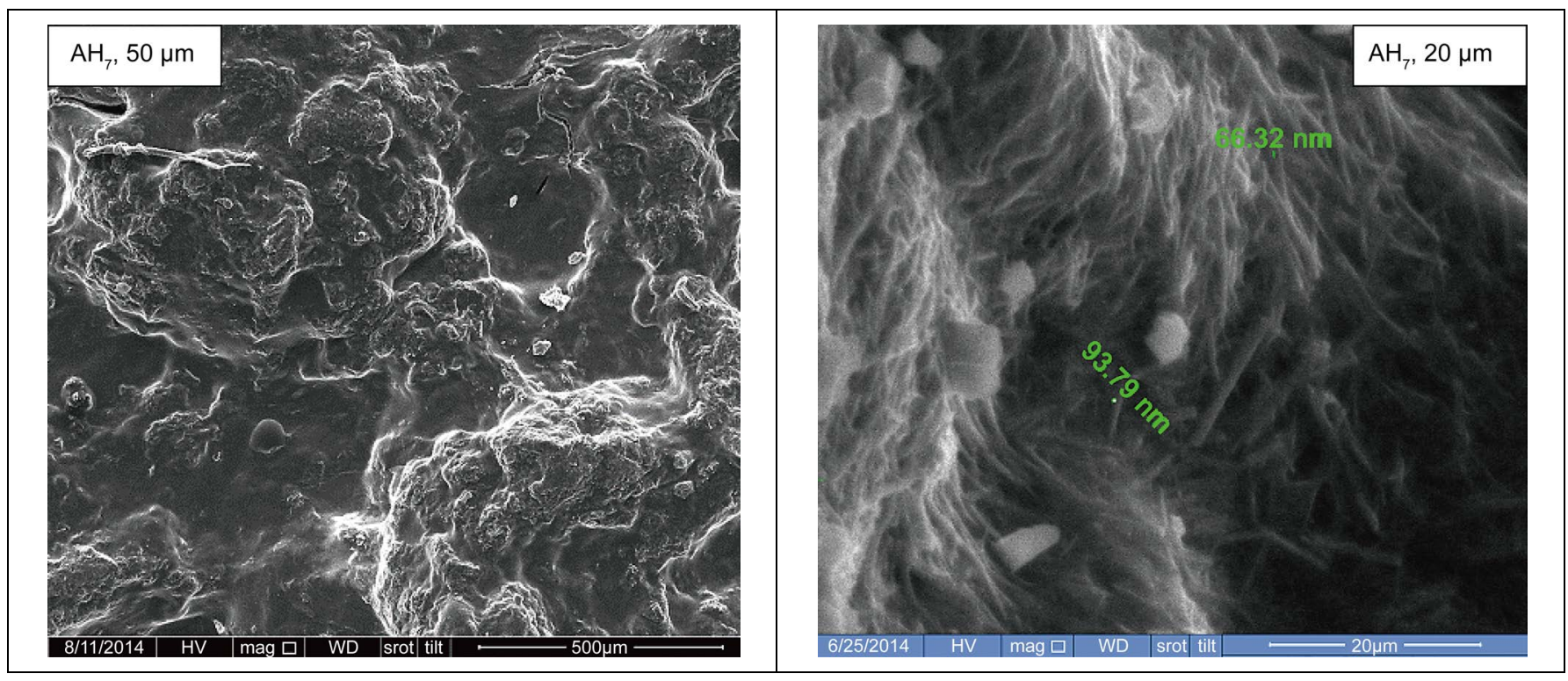

Figure 5. SEM images of fiber $\mathrm{SH}_{1}, \mathrm{SH}_{3}, \mathrm{SH}_{5}$ and $\mathrm{SH}_{7}$ at different amplifications.

such as poly (ethylene glycol) [18]. Therefore, it may need other combinations of polymers, like PEO and Na-alg., to increase the density of fibers on the mesh produced, which is the case here. The SEM micrographs of prepared fiber IPN's revealed that dense materials were obtained.

The relative swelling was determined gravimetrically after immersing uncoated discs in water, Simulated Intestinal Fluid (SIF), and Simulated Gastro Fluid (SGF). The degree of swelling was calculated according to the following equation:

$$
S_{w}(\%)=\left(W_{s}-W_{d}\right) / W_{d} \times 100
$$

where, $W_{s}$ and $W_{d}$ represent the weight of swollen and dry samples, respectively.

The study of swelling of uncoated fiber IPN's affected by a number of varities, including changes in the $\mathrm{pH}$ of immersing solution, different molecular weight of PEG in the triblock copolymers in the IPN's, and changing of PLA chain length. As expected, the swelling ratio of the triblock copolymers increases with an increasing porportion of the hydrophilic block [19] [20].

Results in Figure 6 shows the effect of $\mathrm{pH}$ (8.2,7.2, and 1.2) onto the swelling ratio of the IPN's $\left(\mathrm{SH}_{1}\right)$, Studies of swelling ratio shows that the $\mathrm{pH}$ has a significant effect because it was found that the swelling ratio increased with increasing $\mathrm{pH}$. This can be related to their ability to form ionizable groups $\left(\mathrm{COO}^{-}\right)$in Sodium alginate which leads to increase the bonding characteristics of the fiber IPN's with water.

The swelling ratio increased with increasing poly (ethylene glycol) molecular weight due to increase the hydrophilic polymer chain length of PEG. The swelling ratio for fiber IPN's containing PEG $2000\left(\mathrm{SH}_{1}\right), 4000\left(\mathrm{SH}_{4}\right)$ and $10000\left(\mathrm{SH}_{7}\right)$ are found to be equal to $60 \%, 79 \%$ and $90 \%$ respectively, and the same effect is found for all other fiber IPN's. Figure 7 and Figure 8 are shown examples for this effect. 


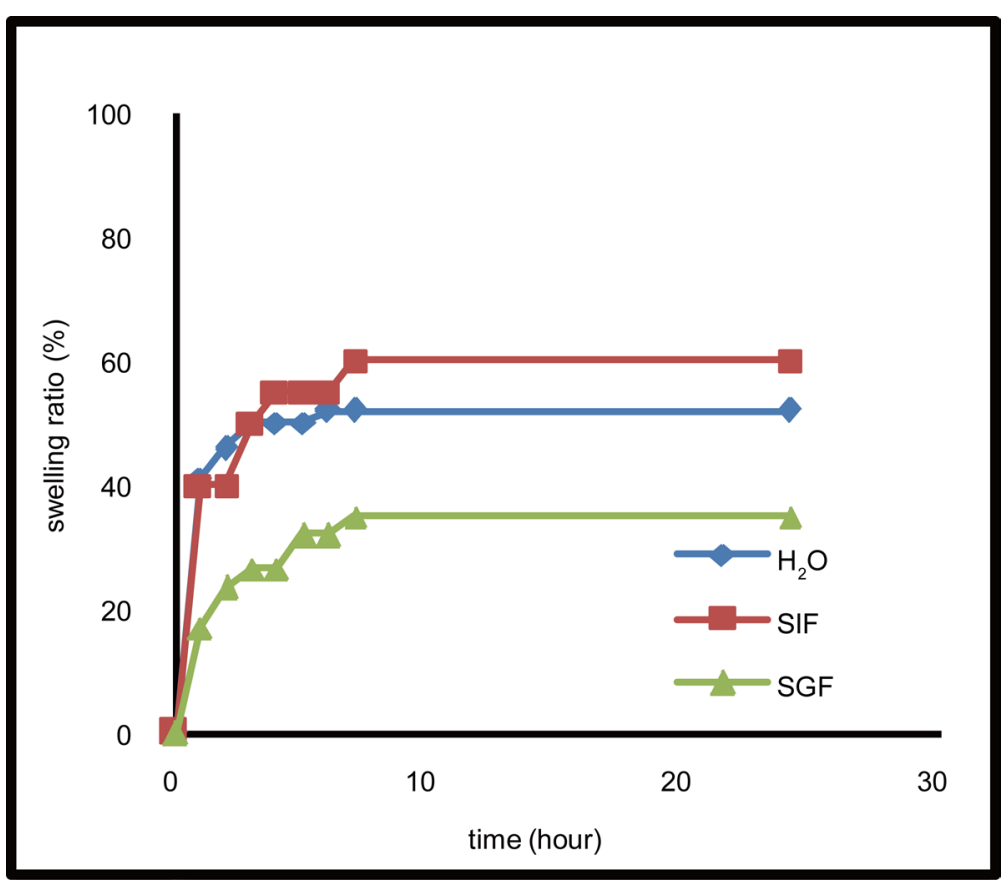

Figure 6. Effect of $\mathrm{pH}$ on swelling ratio of $\mathrm{SH}_{1}$ in (SGF, SIF, and $\mathrm{H}_{2} \mathrm{O}$ ).

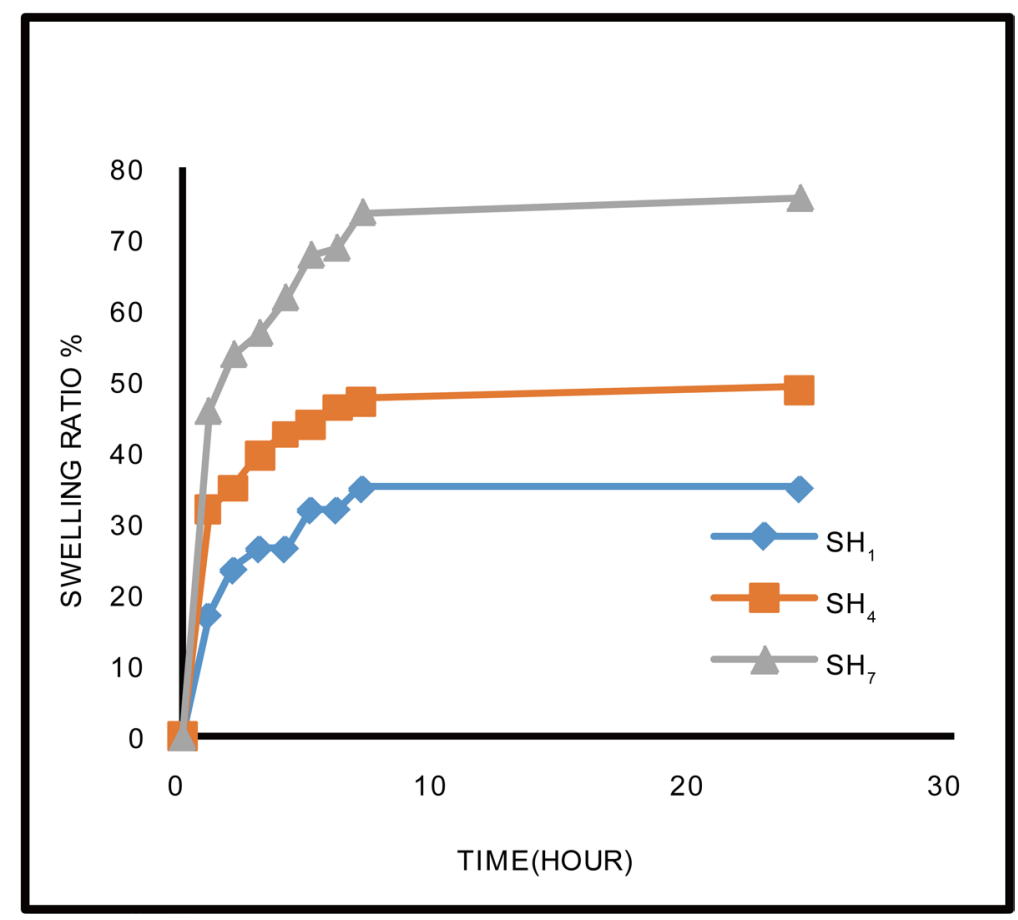

Figure 7. Effect of molecular weight of $\mathrm{PEG}$ on swelling ratio of $\mathrm{SH}_{1}, \mathrm{SH}_{4}$, and $\mathrm{SH}_{7}$ in $\mathrm{SGF}$.

In one series of block copolymer with the same molecular weight of PEG $\left(\mathrm{AL}_{10}, \mathrm{AL}_{25}\right.$ and $\left.\mathrm{AL}_{50}\right)$, the swelling ratio of fiber IPN's $\left(\mathrm{SH}_{1}, \mathrm{SH}_{2}\right.$, and $\left.\mathrm{SH}_{3}\right)$ decreased with increasing of PLA chain length, because of the increasing of LA ratio will increase the hydrophobicity of the copolymers. 
The swelling ratio decreased with increasing lactide chain length because the lactide groups represent the hydrophobic groups in the new triblock copolymer chains leading to decreasing of water uptake from the fiber IPN's. Figure 9 and Figure 10 are exhibited examples of this effect.

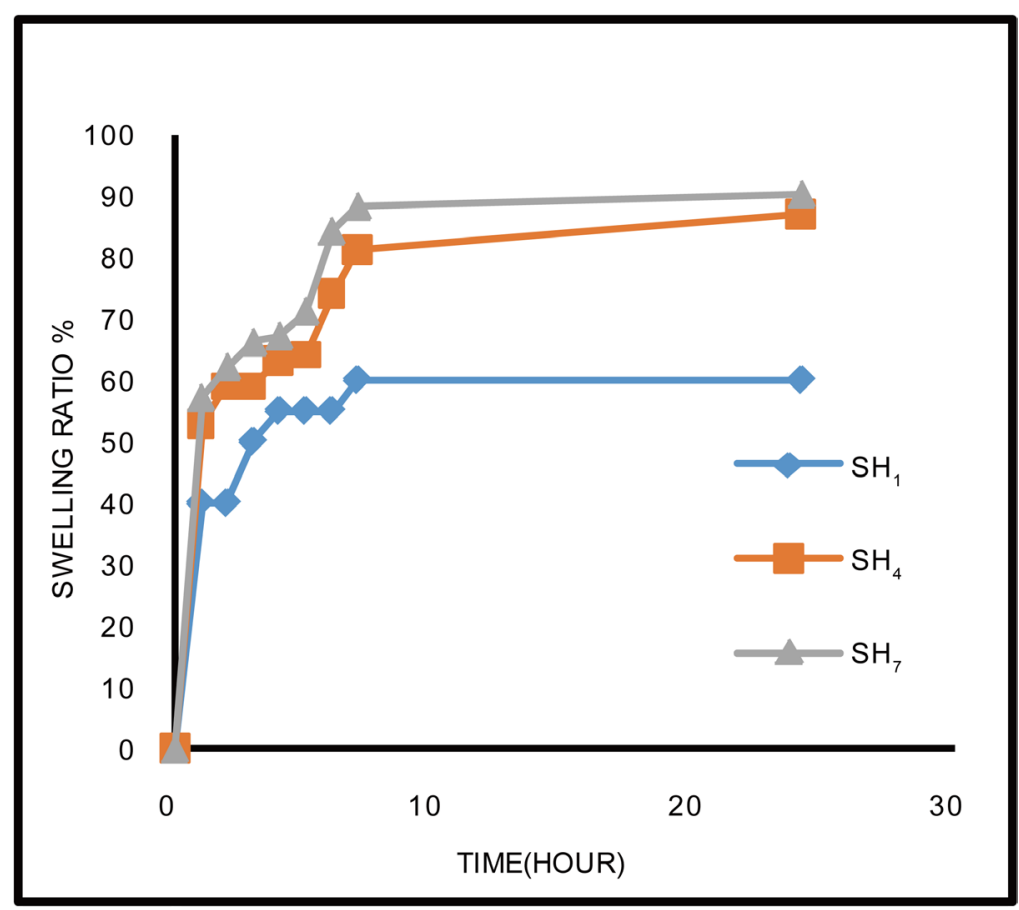

Figure 8. Effect of molecular weight of $\mathrm{PEG}$ on swelling ratio of $\mathrm{SH}_{1}, \mathrm{SH}_{4}$, and $\mathrm{SH}_{7}$ in SIF.

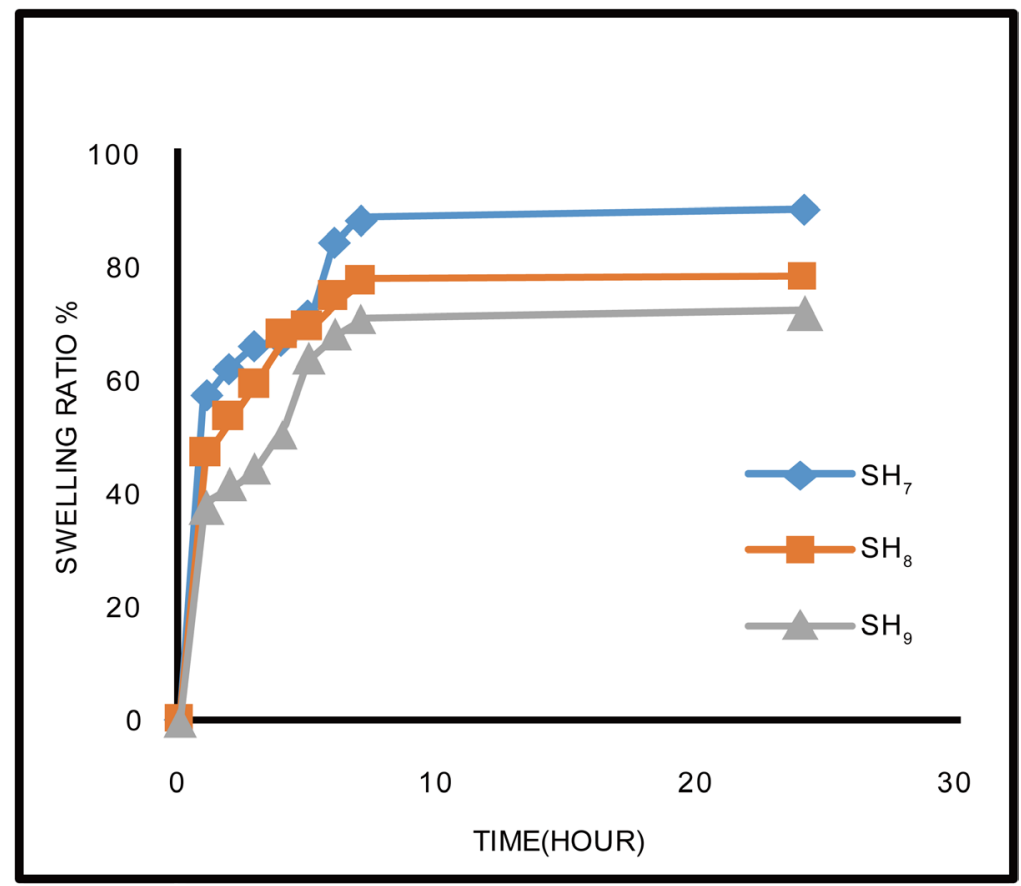

Figure 9. Effect of lactide chain length on swelling ratio of $\mathrm{SH}_{7}, \mathrm{SH}_{8}$ and $\mathrm{SH}_{9}$ in SIF. 


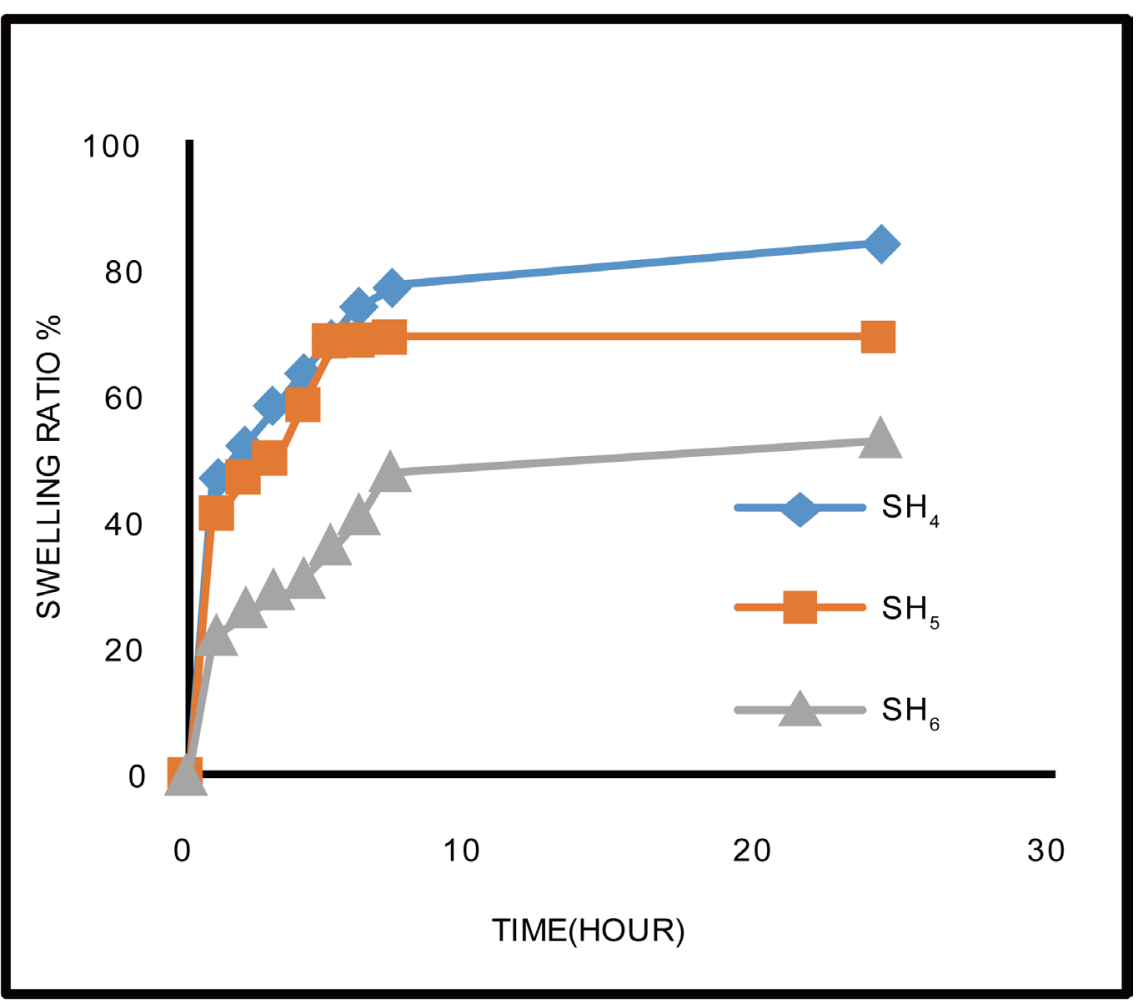

Figure 10. Effect of lactide chain length on swelling ratio of $\mathrm{SH}_{4}, \mathrm{SH}_{5}$ and $\mathrm{SH}_{6}$ in $\mathrm{H}_{2} \mathrm{O}$.

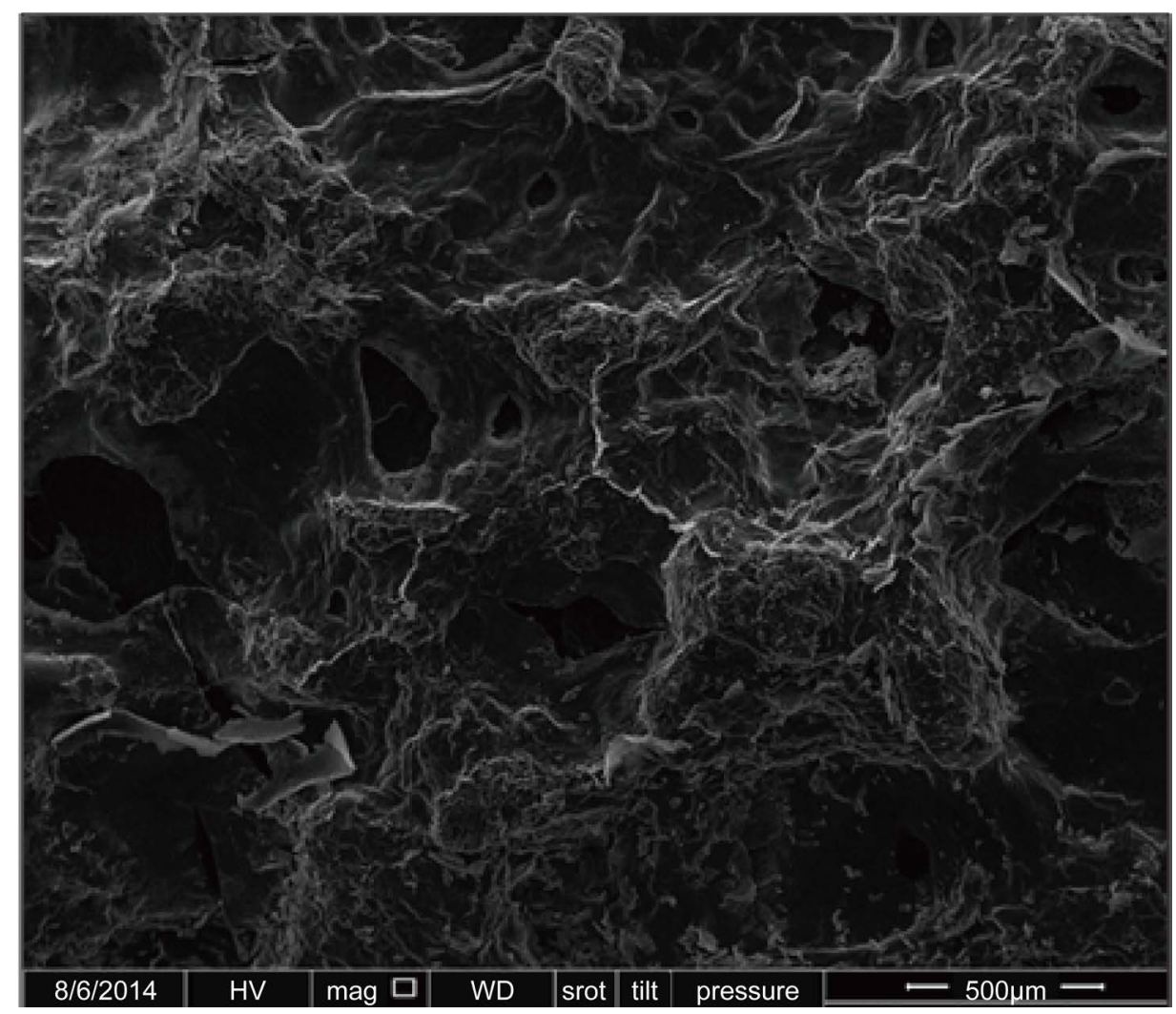

Figure 11. SEM image of swelling fiber $\mathrm{SH}_{9}$ in water. 
The surface of the fiber IPN's prepared was observed in the sinking area, due to the swelling characteristics of poly (ethylene glycol), the size of pores was found to be in the range of (3.406 - 15.346) $\mu \mathrm{m}$, and Figure 11 shows the SEM image of $\mathrm{SH}_{9}$ IPN's in water.

\section{Conclusion}

The spectroscopic characterization revealed that true triblock copolymers were prepared with narrow molecular weight distribution. The swelling results imply the possibility of using these polymeric IPN's in the field of polymer drug delivery especially for Insulin delivery.

\section{References}

[1] He, X., Liang, L., Xie, M., Zhang, Y., Lin, Sh. and Yan, D. (2007) Synthesis of Novel Linear PEO-b-PS-b-PCL Triblock Copolymers by the Combination of ATRP, ROP, and a Click Reaction. Macromolecular Chemistry and Physics, 208, 1797-1802.

[2] Namekawa, S., Suda, S., Yama, H. and Kobyashi, S. (1999) Lipase-Catalyzed Ring-Opening Polymerization of Lactones to Polyesters and Its Mechanistic Aspects. International Journal of Biological Macromolecules, 25, 145-151. https://doi.org/10.1016/S0141-8130(99)00028-8

[3] Kikuchi, H., Uyama, H. and Kobayashi, S. (2002) Lipase-Catalyzed Ring-Opening Polymerization of Substituted Lactones. Polymer Journal, 34, 835-840.

https://doi.org/10.1295/polymj.34.835

[4] Yu, Y., Storti, G. and Morbidelli, M. (2009) Ring-Opening Polymerization L-Lactide: Kinetic and Modeling Study. Macromolecules, 42, 8187-8197. https://doi.org/10.1021/ma901359x

[5] Todd, R. (2013) Catalyst and Monomer Design: Targeting Polymer Properties via Organic Catalyzed Ring Opening Polymerization, Ph.D. Thesis, The University of Warwick, Coventry, UK.

[6] Coulembier, O., Moin, S., Raquez, J., Meyer, F., Mespouille, L. and Duquese, E. (2011) Thermal Degradation of Poly(L-Actide): Accelerating Effect of Residual DBU Based Organic Catalysts. Polymer Degradation and Stability, 96, 739-744.

https://doi.org/10.1016/j.polymdegradstab.2011.02.014

[7] Lohmeijer, B., Pratt, R., Leibfarth, F., Logean, J., Long, D., Dove, A., Nederberg, F., Choi, J., Wade, C., Waymouth, R. and Hedrick, J. (2006) Guanidine and Amidine Organocatalyst for Ring-Opening Polymerization of Cyclic Esters. Macromolecules, 39, 8574-8583. https://doi.org/10.1021/ma0619381

[8] Qian, H., Wohl, A., Crow, J., Macosko, C. and Hoye, T. (2011) Strategy for Control of Random Copolymerization of Lactide and Glycolide: Application to Synthesis of PEG-bPLGA Block Polymers Having Narrow Dispersity. Macromolecules, 44, 7132-7140. https://doi.org/10.1021/ma201169z

[9] Lim, Y., Heo, G., Cho, S. and Wooley, K. (2013) Construction of Reactive Diblock Copolymer, Polyphosphoester-block-poly(L-lactide), as a Versatile Framework for Functional Materials that Capable of full Degradation and Nanoscopic Assembly Formation. ACS Macro Letters, 2, 785-789.

[10] Zepoon, M.H. (2013) Biodegradability Studies of a Dipyl and Sebcoyl Copolymers Prepared with Ethylene Glycol Monomers and Polymers. M.Sc. Thesis, University of Basrah, Basrah, Iraq. 
[11] Wang, D., Fredericks, P., Haddad. A., Hill, J., Rasoul, F. and Whittaker, A. (2011) Hydrolytic Degradation of POSS-PEG-Lactide Hybrid Hydrogels. Polymer Degradation and Stability, 96, 123-130. https://doi.org/10.1016/j.polymdegradstab.2010.10.005

[12] Rachmawati, H. and Permatasari, D. (2008) Development of Papain Microcapsule Using $\mathrm{Na}$-alginate and Study on the in Vitro and ex Vivo Release of Protein from the Microcapsule. 7 th Central European Symposium on Pharmaceutical Technology and Biodelivery Systems, Farmacevtski Vesttnikl, 59, 106.

[13] Mahir A.J. and Al-Lami, H.S. (2014) New Limited Molecular Weight Polymeric Dispersants Prepared by Melt Condensation Polymerization. Chemistry and Materials Research, 6, 12-18.

[14] Zhao, H., Liu, Z., Park, S., Kim, S. and Piao, L. (2012) Preparation and Characterization of PEG/PLA Multiblock and Triblock Copolymer. Bulletin of the Korean Chemical Society, 33, 1638-1642. https://doi.org/10.5012/bkcs.2012.33.5.1638

[15] Singh, V. (2008) Synthesis of Poly Lactide with Varying Moleculare Weight. And Aliphatic Content: Effect of Mosture Sorption. M.Sc. Thesis, Drexel University, Philadelphia, USA.

[16] Patel, A., Gaharwar, A., Iviglia, G., Zhang, H., Mukundan, S., Mihaila, S., Demarchi, D. and Hossein, A.K. (2013) Highly Elastomeric Poly Glycerol Sebacate-co-Poly (Ethylene Glycol) Amphiphilic Block Polymer. Biomaterials, 24, 3970-3983. https://doi.org/10.1016/j.biomaterials.2013.01.045

[17] Reddy R. and Reddy, S. (2010) Effect of Different Co-Polymers on Sodium Alginate Microcapsules Containing Isoniazid. International Journal of PharmTech Research, 2, 21982203.

[18] Caykara, T., Demirci, S., Eroglu, M. and Guven, O. (2005) Poly (Ethylene Oxide) and Its Blends with Sodium Alginate. Polymer, 46, 10750-10757. https://doi.org/10.1016/j.polymer.2005.09.041

[19] Ferruti, P., Penco, M., Addato, D., Ranucci, E. and Deghenghi, R. (1995) Synthesis and Properties of Novel Block Copolymers Containing Poly(Lactic-Glycolic Acid) and Poly (Ethylene Glycol) Segments. Biomaterials, 16, 1423-1428. https://doi.org/10.1016/0142-9612(95)96879-5

[20] Jiang, W. and Schwendeman, S. (2001) Stabilization and Controlled Release of Bovine Serum Albumin Encapsulated in Poly(D, L-Lactide) and Poly(Ethylene Glycol) Microsphere Blends. Pharmaceutical Research, 18, 878-885. https://doi.org/10.1023/A:1011009117586 
Submit or recommend next manuscript to SCIRP and we will provide best service for you:

Accepting pre-submission inquiries through Email, Facebook, LinkedIn, Twitter, etc. A wide selection of journals (inclusive of 9 subjects, more than 200 journals)

Providing 24-hour high-quality service

User-friendly online submission system

Fair and swift peer-review system

Efficient typesetting and proofreading procedure

Display of the result of downloads and visits, as well as the number of cited articles

Maximum dissemination of your research work

Submit your manuscript at: http://papersubmission.scirp.org/

Or contact ojopm@scirp.org 